\title{
Survival of Avulsed Maxillary Incisors Following Delayed Replantation: 3-year Follow-up
}

\author{
E. Radhika, E. Rajendra Reddy, Shaik Hasanuddin \\ Department of Pedodontics and Preventive Dentistry, Government Dental College and Hospital, Hyderabad, Telangana, India \\ Email for correspondence: dr.hasan.shaik@gmail.com
}

\begin{abstract}
A 12-year-old boy had reported with avulsed 11, 12, and 21 after a delay of $12 \mathrm{~h}$. The avulsed teeth were replanted and splinted using an acid-etch composite splint for 4 weeks. Extraoral endodontic therapy was performed before replantation. Before the splint was removed, the root canals were filled with a definite sealer and gutta-percha. The patient was followed up at 1-, 3-, 6-, and 12-month interval and half-yearly thereafter. After 36 months of follow-up, the replanted teeth showed slight clinical mobility, but the roots were being replaced by bone on radiographic examination indicating replacement resorption. The case report concludes that avulsed teeth transported in pasteurized milk, replanted after a delay of $12 \mathrm{~h}$ has a survival rate of 36 months. Replacement resorption is inevitable, wherever delayed replantation is attempted. Prolong delayed replantation serves the esthetic purpose for a young adolescent in the interim phase of developing occlusion.
\end{abstract}

Key words: Avulsion, external root resorption, replacement resorption

\section{INTRODUCTION}

Avulsion of permanent teeth is one of the most serious dental injuries in growing children. External root resorption was most frequently associated with intrusive luxation (92.8\%), followed by avulsion (89.0\%), lateral luxation (80.2\%), and extrusive luxation (77.4\%). Replacement resorption was observed more frequently in cases of avulsion (87.2\%). ${ }^{[1]}$ The progression of the disease process post-ankylosis, leading to inflammatory and replacement resorption, is well documented in different clinical conditions. ${ }^{[2]}$ The present case report discusses the long-term prognosis/survival of a case of delayed replantation of avulsed incisors, which were replanted after prolonged dry, extraalveolar time (more than $12 \mathrm{~h}$ ).

\begin{tabular}{|c|c|}
\hline \multirow{3}{*}{ Quick Response Code } & Article Info: \\
\hline & doi: $10.5866 / 2017.9 .10176$ \\
\hline & $\begin{array}{l}\text { Received: } 13-07-2017 \\
\text { Revised: } 23-08-2017 \\
\text { Accepted: 05-09-2017 } \\
\text { Available Online: } 27-11-2017 \text { (www.nacd. } \\
\text { in)@ NAD, } 2017 \text { - All rights reserved }\end{array}$ \\
\hline
\end{tabular}

\section{CASE REPORT}

A 12-year-old boy had reported to the department of pedodontics and preventive dentistry with avulsed teeth, carried in pasteurized milk. On extraoral examination, signs of swelling and lacerations on the anterior maxillary region were evident. Intraoral examination showed avulsed maxillary right central and lateral incisors and maxillary left central incisor [Figure 1]. The avulsed teeth were gently debrided with saline to remove necrotic tissues and any other surface contaminants and were placed in doxycycline solution for $20 \mathrm{~min}$. The patient had no relevant medical history.

The available treatment options were explained to the patient and his parents with the possible treatment outcome, and it was decided to replant the avulsed teeth in the mouth for as long as possible. After obtaining an informed consent, the treatment was initiated. Local anesthesia was achieved, and the alveolar sockets were gently irrigated with saline to remove any granulation tissue. Extraoral endodontic therapy was performed before replantation. Conventional extirpation, enlargement, and cleaning of root canals were performed, and calcium hydroxide dressing was placed. 
Teeth were replanted into the respective sockets with slight digital pressure. Once the teeth were properly seated in the socket, they were checked for alignment and were stabilized with adjacent teeth using an acid-etch composite resin splint for 4 weeks [Figure 2]. Postoperatively, systemic antibiotic therapy was initiated for 5 days. The patient was advised to take soft diet and to brush with a soft bristle toothbrush. Before the splint was removed, the root canals were filled with definite zinc oxide-eugenol sealer and gutta-percha points [Figure 3]. The composite splint was removed after 4 weeks, and composite resin restorations were done for the fractured crowns. The teeth did not show any clinical symptoms such as pain, tenderness, mobility, and any type of root resorption in the following months.

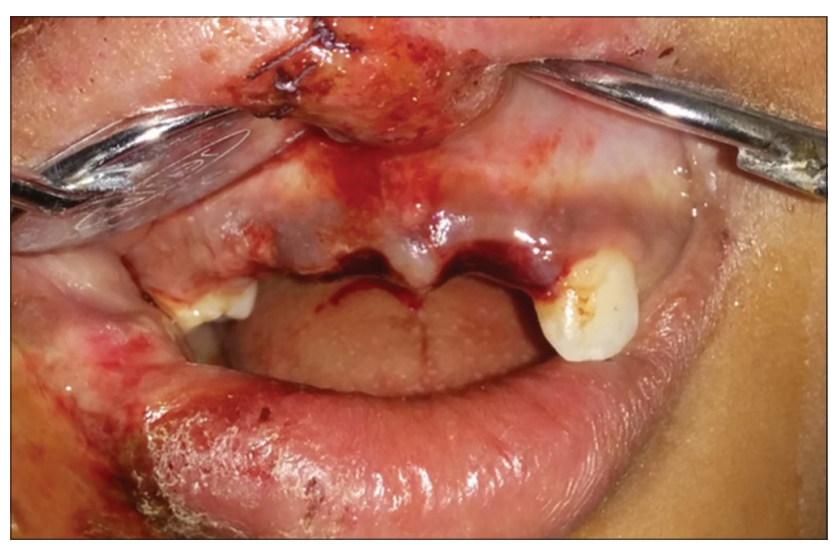

Figure 1: Pre-operative photograph showing avulsed maxillary right, left central incisors, and right lateral incisor from its alveolar socket

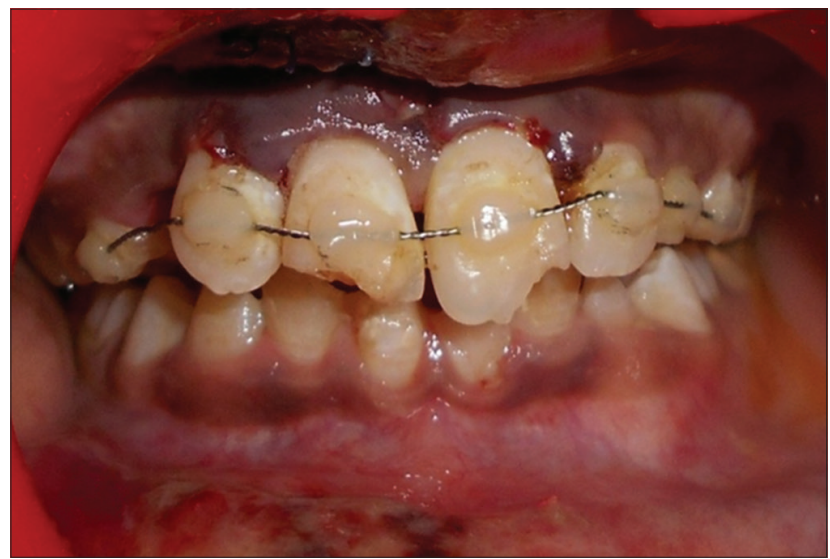

Figure 2: Clinical picture showing delayed replantation followed by acid-etch composite splinting

\section{Follow-up}

The patient was followed up at 1-, 3-, 6-, and 12-month interval and half-yearly thereafter for examination of the replanted tooth clinically and radiographically. The teeth were asymptomatic and the follow-up period lasted for more than 36 months. After 24 months, the replanted teeth did not show any clinical mobility, but the roots were being replaced partially by the bone on radiographic examination [Figure 4]. After 36-month follow-up, on clinical examination, the replanted teeth did not show any gingival distortion or clinical mobility, but the roots were being replaced by the

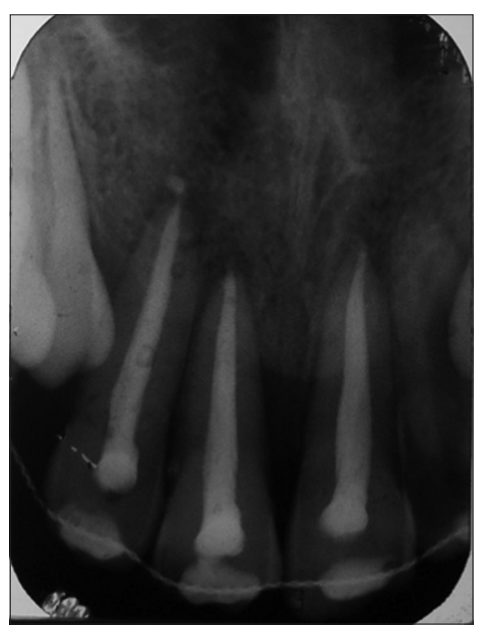

Figure 3: Photograph of an intraoral periapical radiograph after the completion of endodontic treatment by definite sealer and gutta-percha

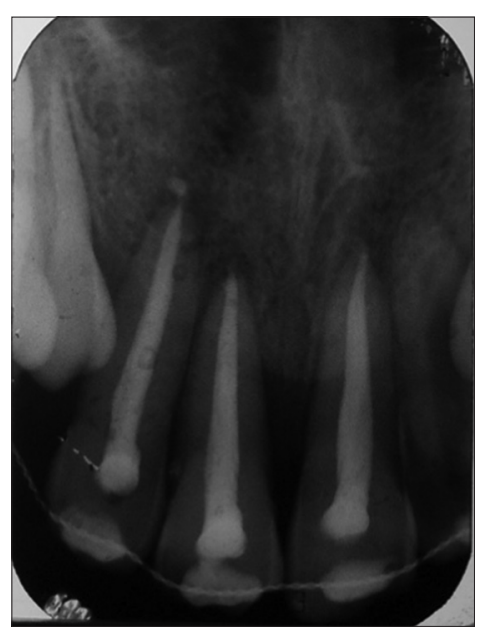

Figure 4: Photograph of an intraoral periapical radiograph after 2-year follow-up, revealing the roots being replaced partially by the bone 
bone on radiographic examination [Figure 5]. The lamina dura is lost around the root as it becomes incorporated in the bone, indicating replacement resorption. Hence, a final composite restoration was done to the incisors [Figure 6].

\section{DISCUSSION}

Reimplantation of avulsed incisors after a considerable delay of more than 60 min has a proven compromised prognosis. However, it is often attempted, even when the delay is more than $12-24 \mathrm{~h}$. Hence, in the present case report, replantation was carried out after $12 \mathrm{~h}$ of delay, as the avulsed teeth were transported in pasteurized milk. The evidence appears inconclusive to confirm any association between short-term splinting

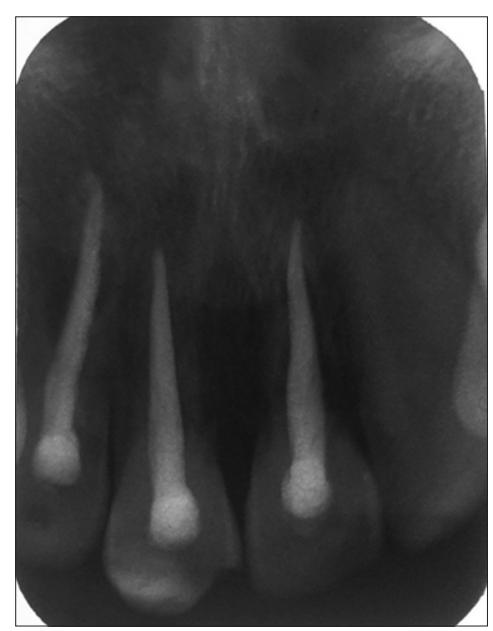

Figure 5: Photograph of an intraoral periapical radiograph after 3 years of follow-up showing the roots being replaced by bone

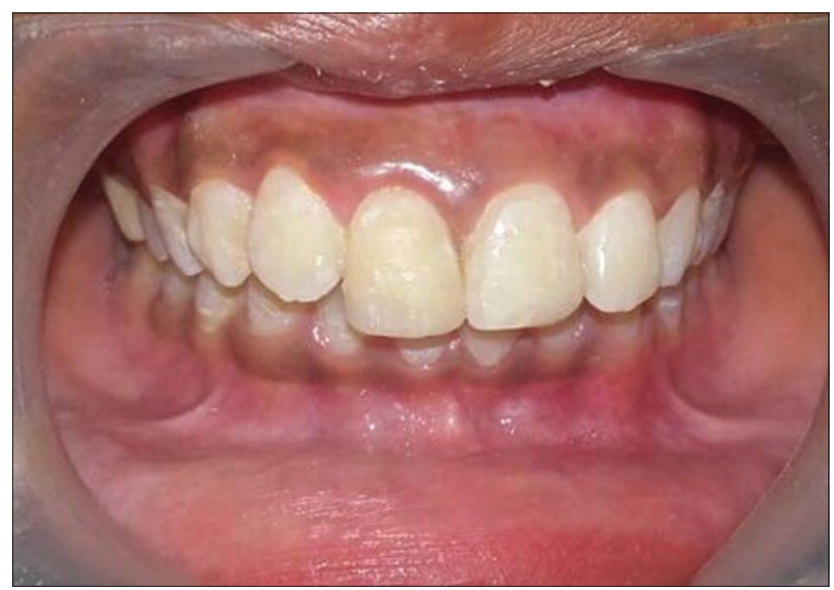

Figure 6: Clinical picture showing final composite restoration of central incisors after a follow-up of 3 years and increased likelihood of functional periodontal healing or decreased incidence of replacement resorption. ${ }^{[3]}$ Hence, in the current case report, acid-etch composite splint had been placed for 4 weeks, as per the guidelines recommended by the International Association of Dental Traumatology (IADT), endorsed by the American Academy of Pediatric Dentistry. ${ }^{[4]}$

Endodontic therapy is performed before replantation if there is a delay of more than $2 \mathrm{~h}$, and where apex formation is complete, it should be commenced within 10 days after replantation. ${ }^{[5}$ According to the guidelines given by the IADT, if the extraalveolar dry time is more than $60 \mathrm{~min}$ before replantation, extraoral root canal treatment can be carried out before replantation. ${ }^{[4]}$ Hence, in the present case report, extraoral endodontic therapy was carried out before replantation, but obturation of root canals was performed after the teeth were stabilized in the sockets.

Sequela of delayed replantation is a well-known phenomenon, i.e., ankylosis followed by external root resorption. Root resorption is physiologic in deciduous teeth but is considered to be pathological in permanent teeth. ${ }^{[6]}$ Dehydration, PDL cellular vitality, and mechanical trauma, all affect the prognosis of a replanted tooth. PDL vitality is the primary factor in the prevention of ankylosis. ${ }^{[7]}$ In avulsion, damage to PDL is more severe, and hence, replacement resorption is evident in most of the cases. Replacement resorption leads to fusion of tooth root with adjacent alveolar bone. In older children, the process produces bony replacement of root cementum and root dentin, i.e., replacement resorption eventually results in loss of the crown either spontaneously or by surgical intervention. ${ }^{[6]}$ Similar kind of replacement resorption is evident in the current case report [Figure 6].

It has been reported that replacement resorption is 16 times more probable in replanted teeth when related to mobility impairment. The longer the period before replantation, the higher the chance of development of replacement resorption. ${ }^{[8]}$ The absence of periodontal ligament (PDL) can stimulate bone cells to form new tissue, remodeling the traumatized area. In delayed replantation, healing occurs by repair rather than by regeneration. In the present case report, healing might have occurred by repair. 
When there are no PDL remnants and root contamination is under control, replacement resorption and ankylosis are the best results followed. Although these events will end up leading to tooth loss, this will happen slowly without any loss of alveolar ridge height, which is considered important for future prosthesis planning. Hence, in the present case report, tooth replantation is done, even after a prolonged delay to prevent loss of alveolar ridge height.

\section{CONCLUSION}

The case report concludes that avulsed teeth transported in pasteurized milk, replanted after a delay of $12 \mathrm{~h}$ has a survival rate of more than 36 months. Postponement of final obturation with gutta-percha after initial extraoral biomechanical preparation serves in performing better obturation and delaying rootresorption. Replacementresorption is inevitable, wherever delayed replantation is attempted. Prolong delayed replantation serves the esthetic purpose for a young adolescent in the interim phase of developing occlusion to boost his/ her self-esteem.

\section{REFERENCES}

1. Soares AJ, Souza GA, Pereira AC, Vargas-Neto J, Zaia AA, Silva EJ. Frequency of root resorption following trauma to permanent teeth. J Oral Sci 2015;57:73-8.

2. Finucane D, Kinirons MJ. External inflammatory and replacement resorption of luxated, and avulsed replanted permanent incisors: A review and case presentation. Dent Traumatol 2003;19:170-4.

3. Evans D. Splinting duration for replanted avulsed teeth. Evid Based Dent 2009;10:104

4. Andersson L, Andreasen JO, Day P, Heithersay G, Trope M, Di Angelis AJ, et al. International association of dental traumatology guidelines for the management of traumatic dental injuries: Avulsion of permanent teeth. Dent Traumatol 2012;28:88-96

5. Heithersay GS. Replantation of avulsed teeth. A review. Aust Dent J 1975;20:63-72.

6. Barrett EJ, Kenny DJ. Survival of avulsed permanent maxillary incisors in children following delayed replantation. Endod Dent Traumatol 1997;13:269-75.

7. Bakland LK. Root resorption. Dent Clin North Am 1992;36:491-507.

8. Sapir S, Shapira J. Decoronation for the management of an ankylosed young permanent tooth. Dent Traumatol 2008;24:131-5. 